\title{
IN FIELD ASSESSMENT ON THE RELATIONSHIP BETWEEN PHOTOSYNTHETIC ACTIVE RADIATION (PAR) AND GLOBAL SOLAR RADIATION TRANSMITTANCE THROUGH DISCONTINUOUS CANOPIES
}

\author{
Ricardo Oyarzún ${ }^{1,2 *}$, Claudio Stöckle ${ }^{1}$, Joan Wu ${ }^{1}$, and Matthew Whiting ${ }^{3}$
}

\begin{abstract}
In many crop models, the process of radiation transmittance through the canopy is normally described as an exponential attenuation process (Beer's Law equation), which is assumed to be valid for canopies covering the ground with a random spatial distribution of leaves. However, for discontinuous canopies, where a distinctive row pattern of plant exists, there is a more complex situation because of the presence of gaps between individual plants. This must be accounted for when characterizing radiation relationships for these kinds of systems, in particular when short time-scales are of interest. Photosynthetically active radiation (PAR) transmittance $\left(\tau_{\mathrm{PAR}}\right)$ is more commonly studied and reported than global solar radiation $\left(S_{\mathrm{g}}\right)$ transmittance $\left(\tau_{\mathrm{Sg}}\right)$. However, both PAR and $\mathrm{S}_{\mathrm{g}}$ are important in radiative transfer sub-models used in plant growth simulation. In this work simultaneous measurements of $\tau_{\mathrm{Sg}}$ and $\tau_{\text {PAR }}$ under discontinuous canopies were performed, and the hourly changes in radiation transmittance for PAR and global solar radiation were characterized. Two methods were assessed to transform between $\tau_{\mathrm{Sg}}$ and $\tau_{\mathrm{PAR}}$. The two methods yielded similar results for low values of transmittance, but disagreement occurred for higher values of transmittance. The method based on a fixed value for the ratio of extinction coefficients for PAR and $\mathrm{S}_{\mathrm{g}}$ outperformed the method based on a linear relationship between $\tau_{\mathrm{PAR}}$ and $\tau_{\mathrm{Sg}}$ with average relative errors $(\mathrm{RE})$ of $7.97 \%$ vs. $13.29 \%$ and $2.84 \%$ vs. $7.77 \%$ for hourly and daily time-scale, respectively.
\end{abstract}

Key words: radiation interception, extinction coefficient, crop simulation model.

\section{INTRODUCTION}

Radiation transmittance through crop canopies is normally described as exponential-type attenuation process as (Thornley and Johnson, 1990; Lizaso et al., 2003):

$$
\tau=\mathrm{I}_{(\mathrm{l})} / \mathrm{I}_{(\mathrm{o})}=\mathrm{e}^{-\mathrm{K} \text { LAIo }}
$$

where $\tau$ is the transmittance in the wavelength of interest, $I_{(1)}$ is the transmitted radiation, $I_{(o)}$ is the incoming

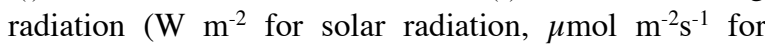
photosynthetically active radiation $\mathrm{PAR}$ ), $\mathrm{LAI}_{\mathrm{o}}$ is the leaf area index $\left(\mathrm{m}^{2}\right.$ leaves per $\mathrm{m}^{2}$ of soil), and $\mathrm{K}$ is an extinction coefficient. This equation is generally assumed to be valid for full covering canopies with random

${ }^{1}$ Washington State University, Biological Systems Engineering Faculty, Pullman, Washington, 99163, USA.

${ }^{2}$ Universidad de La Serena, Facultad de Ingeniería, Benavente 980, La Serena, Chile. "Corresponding author (royarzun@userena.cl).

${ }^{3}$ Washington State University, Irrigated Agriculture Research and Extension Center, Prosser, Washington, 99350, USA.

Received: 3 January 2010.

Accepted: 11 September 2010. distribution of leaves. For discontinuous canopies, such as those found in crops with row structure or in fruit tree orchards, a clumping factor $(\Omega)$, which varies between 0 and 1 , is often included to extend the use of the equation (Campbell and Norman, 1998). Thus, Equation [1] is rewritten as:

$$
\tau=\mathrm{e}^{-\mathrm{K} \Omega \text { LAIo }}
$$

Although questioned (Sinclair, 2006), it is fairly common to find studies that characterize either diurnal radiation transmittance or interception by crop canopies based only on midday observations (Yunusa et al., 1997; Kiniry, 1999). This practice may seem valid for horticultural and annual crops that tend to develop and reach full soil cover rather quickly. However, a different situation might be expected for discontinuous crop canopies, such as those existing in fruit tree orchards or horticultural crops on early growing stages. In such systems, radiation transmittance processes are affected by both the fraction of the radiation that passes through the canopy, and therefore is attenuated, and the fraction of the radiation 
that passes unobstructed through and between canopy gaps, which varies greatly through the day. This is of particular significance for radiation transfer on short-time scales, with varying interaction between the crop canopy architecture and the sun position in the sky throughout the day.

Furthermore, radiative transfer sub-models that can be used in plant growth simulations must take into account canopy transmittance or interception of PAR (400 to $700 \mathrm{~nm}$ wavelength) as well as global solar radiation $\left(\mathrm{S}_{\mathrm{g}}, 300\right.$ to $\left.3000 \mathrm{~nm}\right)$. The former is required to calculate photosynthesis, while the latter is used to calculate crop energy balance and crop evapotranspiration and its partitioning into transpiration and soil water evaporation (Weiss and Norman, 1985; Stöckle and Jara, 1998). Moreover, the radiationuse efficiency (RUE) approach that relates dry mass accumulation with the amount of intercepted PAR (Monteith, 1994; Kiniry, 1999), or intercepted Sg (Castellan-Estrada, 2001) is widely used to estimate biomass accumulation in horticultural crops, fruit trees and forest (Landsberg and Hingston, 1996; Kiniry et al., 1998; Mariscal et al., 2000).

Simultaneous direct measurements of PAR transmittance $\left(\tau_{\mathrm{PAR}}\right)$ and $\mathrm{S}_{\mathrm{g}}$ transmittance $\left(\tau_{\mathrm{Sg}}\right)$ are rarely done in the field or found in the literature, since instruments need to be placed under leaf canopies and left there for the whole measurement period (Sinclair, 2006). Studies are more commonly performed for PAR than $S_{\mathrm{g}}$, due to the easiness of its measurement and instrument availability. Thus, the question arises in how to convert between $\tau_{\mathrm{PAR}}$ and $\tau_{\mathrm{sg}}$. This issue was addressed by Campbell and Van Evert (1994), who proposed a theoretical method based upon the different leaf optical properties of crop leaves regarding different portion of the radiation spectrum, which determines a ratio for the extinction coefficients for $\mathrm{S}_{\mathrm{g}}$ and PAR $\left(\mathrm{K}_{\mathrm{Sg}} /\right.$
$\mathrm{K}_{\mathrm{PAR}}$ ) of 0.7 . This is done considering leaf absorptivities for PAR and $\mathrm{S}_{\mathrm{g}}$ of 0.8 and 0.4 , respectively. From their work, some authors later adopted the same method and value for this ratio on studies reported for horticultural and annual crops (Jovanovic et al., 1999; Jovanovic and Annandale, 2000; Marcos, 2000). In an independent theoretical effort, Kiniry (1999) gave values of $\mathrm{K}_{\mathrm{Sg}}$ and $\mathrm{K}_{\mathrm{PAR}}$ that determine a figure of 0.75 for the same ratio. However, when considering the conversion of RUE values based on PAR into RUE based on $S_{\mathrm{g}}$, Bonhomme (2000) argued that the use of a single conversion factor would not be suitable for different situations of LAI and leaf orientations. Nevertheless, a common aspect of these studies is that they relied on theoretical calculations. As pointed out by Yunusa et al. (1993), and later by Sattin et al. (1997), there is a lack of experimental, field-obtained data on this subject.

The purposes of this research were: (i) to study and characterize the diurnal variation of $\tau_{\mathrm{PAR}}$ and $\tau_{\mathrm{Sg}}$, associated with discontinuous canopies; and (ii) to experimentally assess the suitability of reported methods to convert $\tau_{\mathrm{PAR}}$ into $\tau_{\mathrm{Sg}}$ for discontinuous canopies.

\section{MATERIALS AND METHODS}

\section{Experimental conditions}

Field measurements were carried out in selected clear days from May to July in the summer of 2004 at the Roza experimental orchards of Washington State UniversityIrrigated Agriculture Research and Extension Center (WSU-IAREC) near Prosser $\left(46.2^{\circ} \mathrm{N}, 119.7^{\circ} \mathrm{W}, 380\right.$ m.a.s.1.), Washinton, USA. They were performed on a mature sweet cherry (Prunus avium L.) orchard, and on a corn (Zea mays L.) crop during early stages of development, under variable experimental conditions in terms of both sun position through the day (cherry dataset) and canopy cover (corn dataset), as shown in Table 1.

Table 1. Days and experimental conditions of field measurements, in terms of sun position (zenith and azimuth angles, in degrees) at three different hours (standard time), leaf area index $\left(\mathrm{LAI}_{0}\right)$, and incoming global radiation $\left(\mathrm{S}_{\mathrm{g}}\right.$, $\mathrm{MJ}$ $\left.\mathbf{m}^{-2} \mathbf{d}^{-1}\right)$.

\begin{tabular}{|c|c|c|c|c|c|c|c|c|c|}
\hline \multirow[b]{2}{*}{ Crop } & \multirow{2}{*}{$\begin{array}{l}\text { Date } \\
\text { (DOY) }\end{array}$} & \multicolumn{3}{|c|}{ Zenith angle } & \multicolumn{3}{|c|}{ Azimuth angle $^{1}$} & \multirow[b]{2}{*}{$\mathbf{L A I}_{0}$} & \multirow[b]{2}{*}{$\mathrm{Sg}$} \\
\hline & & 09:00 & $12: 00$ & 15:00 & 09:00 & $12: 00$ & $15: 00$ & & \\
\hline \multirow[t]{3}{*}{ Sweet cherry } & May 9 (130) & 46.4 & 28.8 & 47.5 & 66.6 & 358.2 & 291.7 & 2.65 & $26.9^{2}$ \\
\hline & June 1 (153) & 43.2 & 24.1 & 43.9 & 71.5 & 358.8 & 287.5 & 3.21 & 25.3 \\
\hline & July 10 (192) & 44.9 & 24.0 & 42.6 & 73.4 & 3.0 & 289.1 & 3.47 & 27.0 \\
\hline \multirow[t]{3}{*}{ Corn } & July 1 (183) & 43.5 & 23.1 & 42.2 & 74.0 & 2.3 & 287.8 & 1.75 & $25.7^{3}$ \\
\hline & July 7 (189) & 44.0 & 23.6 & 42.4 & 73.7 & 2.8 & 288.6 & 0.71 & 24.6 \\
\hline & July 16 (198) & 45.7 & 25.8 & 43.7 & 71.9 & 3.4 & 291.2 & 1.20 & 25.3 \\
\hline
\end{tabular}

\footnotetext{
${ }^{1}$ Angles were measured from due South, increasing counterclockwise.

${ }^{2}$ Total incoming radiation between 07:00 and 17:00 h.

${ }^{3}$ Total incoming radiation between 08:00 and 16:00 h; DOY: day of the year.
} 


\section{Cherry trees}

Measurements were made on 9 yr-old 'Bing'/'Gisela $5{ }^{\circledR}$ ' sweet cherry trees spaced at $2.5 \mathrm{~m}$ by $4.5 \mathrm{~m}$ within and between rows, respectively, in North-South oriented rows, trained to a free standing, standard multiple-leader open-center architecture, forming a nearly continuous hedgerow of $3.2 \mathrm{~m}$ tall and $2.8 \mathrm{~m}$ width. Leaf area of the trees $\left(\mathrm{L}_{\mathrm{t}}\right)$ was estimated non-destructively along the season as the sum of spur leaf area $\left(\mathrm{L}_{\mathrm{p}}\right)$ and shoot leaf area $\left(L_{s}\right)$ following the technique outlined in Whiting (2001).

Simultaneous $\tau_{\text {PAR }}$ and $\tau_{\text {Sg }}$ measurements were carried out on May 9 (DOY 130), June 1 (DOY 153), and July 10 (DOY 192), 2004, at two locations in the orchard (Figure 1). PAR transmittance was measured hourly from 07:00 to $17: 00 \mathrm{~h}$ (standard time), using a $0.8 \mathrm{~m}$ linear quantum sensor (AccuPAR probe, Decagon Devices, Pullman, Washington, USA). At each hour, incoming PAR ( $\left.\mathrm{PAR}_{\mathrm{h}}\right)$ was determined on an open area near the trees. This was done twice on each measurement period, i.e. immediately before and after the "below-canopy" measurements,

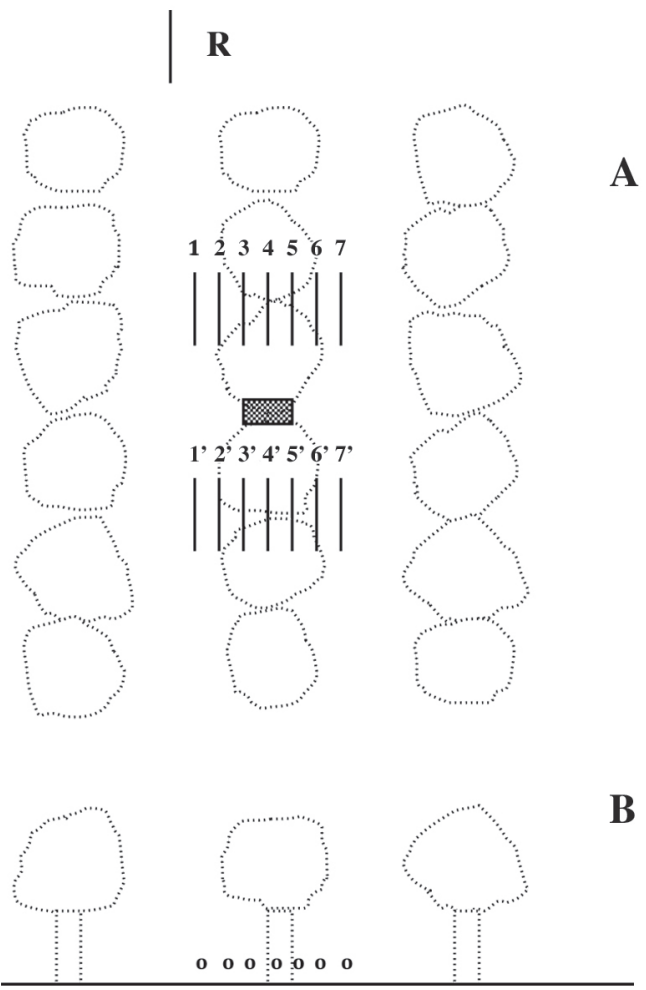

Figure 1. Schematic representation of the disposition of the solarimeters on the two locations on the orchard in A plan view, and in B cross-section view, as well as the location of the reference solarimeter measuring incoming solar radiation $R$, and the datalogger unit (shadowed rectangle). The photosynthetically active radiation (PAR) sensor was hand-moved through the same positions for measurements. The same procedure was used for the corn field. the average value was calculated and a mean time was assigned. Hourly below-canopy PAR measurements $\left(\mathrm{PAR}_{\mathrm{h} \downarrow}\right)$ were taken at $30 \mathrm{~cm}$ above the orchard floor on seven positions parallels to the tree row and separated by $65 \mathrm{~cm}$, with the fourth measurement at the tree row center, by hand-moving the probe from one position to another, following Cohen et al. (1997). Individual and average readings $\left(\mathrm{PAR}_{\mathrm{h} \downarrow} \downarrow\right.$ and $\mathrm{PAR}_{\mathrm{h}, \mathrm{avg} \downarrow} \downarrow$, respectively) were recorded. The fractional PAR transmittance on each hour $\left(\tau_{\mathrm{PAR}, \mathrm{h}}\right)$ and the PAR extinction coefficient $\left(\mathrm{K}_{\mathrm{PAR}, \mathrm{h}}\right)$ were determined as:

$$
\begin{gathered}
\tau_{\mathrm{PAR}, \mathrm{h}}=\mathrm{PAR}_{\mathrm{h}, \mathrm{avg}} \downarrow / \mathrm{PAR}_{\mathrm{h}} \\
\mathrm{K}_{\mathrm{PAR}, \mathrm{h}}=\left(-\ln \tau_{\mathrm{PAR}, \mathrm{h}}\right) / \mathrm{LAI}_{\mathrm{o}}
\end{gathered}
$$

it should be noted that $\mathrm{K}_{\mathrm{PAR}, \mathrm{h}}$ is an effective extinction coefficient, and it already includes the effect of gaps between canopies, since it is obtained from field measured $\tau_{\mathrm{PAR}, \mathrm{h}}$ and $\mathrm{LAI}_{\mathrm{o}}$. Thus, it corresponds to the product of $\mathrm{K}$ and $\Omega$ showed in Equation [2].

Daily weighted average PAR transmittance $\left(\tau_{\text {PAR,D }}\right)$ and extinction coefficient $\left(\mathrm{K}_{\mathrm{PAR}, \mathrm{D}}\right)$ were obtained as:

$$
\begin{aligned}
\tau_{\mathrm{PAR}, \mathrm{D}} & =\sum_{\mathrm{h}=1}^{11} \tau_{\mathrm{PAR}, \mathrm{h}} \mathrm{PAR}_{\mathrm{h}} / \sum_{\mathrm{h}=1}^{11} \mathrm{PAR}_{\mathrm{h}} \\
\mathrm{K}_{\mathrm{PAR}, \mathrm{D}} & =\sum_{\mathrm{h}=1}^{11} \mathrm{~K}_{\mathrm{PAR}, \mathrm{h}} \mathrm{PAR}_{\mathrm{h}} / \sum_{\mathrm{h}=1}^{11} \mathrm{PAR}_{\mathrm{h}}
\end{aligned}
$$

Global solar radiation transmittance was assessed on the same positions as described above for $\tau_{\mathrm{PAR}}$, but using seven $0.9 \mathrm{~m}$ long solarimeter tubes (Marcos, 2000) per location, permanently installed throughout each day. An additional solarimeter tube was placed in an open area next to the orchard and was used to register the incoming solar radiation $\left(\mathrm{Sg}_{\mathrm{h}}\right)$. All the solarimeters used were calibrated against a Precision Eppley thermopile pyranometer (The Eppley Laboratory, Newport, Rhode Island, USA).

The solarimeters were connected to a CR10 datalogger (Campbel Scientific, Logan, Utah, USA). A scan rate of $30 \mathrm{~s}$ was used and signals were averaged every $5 \mathrm{~min}$, and data were recorded every 60 min coincidental with PAR measurements were considered for the analysis. Similar to PAR measurements, the global radiation transmittance $\left(\tau_{\mathrm{Sg}, \mathrm{h}}\right)$ and the extinction coefficient $\left(\mathrm{K}_{\mathrm{Sg}, \mathrm{h}}\right)$ were obtained for each hour as:

$$
\begin{aligned}
\tau_{\mathrm{Sg}, \mathrm{h}} & =\mathrm{Sg}_{\mathrm{h}, \mathrm{avg}} / \mathrm{Sg}_{\mathrm{hr}} \\
\mathrm{K}_{\mathrm{Sg}, \mathrm{hr}} & =\left(-\ln \tau_{\mathrm{Sg}, \mathrm{h}}\right) / \mathrm{LAI}_{\mathrm{o}}
\end{aligned}
$$


where $S g_{h, a v g} \downarrow$ is the average value obtained from the below-canopy solarimeter tubes. Similarly, $\mathrm{K}_{\mathrm{Sg}}$ represents the effective extinction coefficient. The respective daily averages were obtained as:

$$
\begin{aligned}
\tau_{\mathrm{gg}, \mathrm{D}} & =\sum_{\mathrm{h}=1}^{11} \tau_{\mathrm{Sg}_{\mathrm{g}} \mathrm{h}} \mathrm{Sg}_{\mathrm{h}} / \sum_{\mathrm{h}=1}^{11} \mathrm{Sg}_{\mathrm{h}} \\
\mathrm{K}_{\mathrm{g}, \mathrm{D}} & =\sum_{\mathrm{h}=1}^{11} \mathrm{~K}_{\mathrm{Sg}_{\mathrm{g}} \mathrm{h}} \mathrm{Sg}_{\mathrm{h}} / \sum_{\mathrm{h}=1}^{11} \mathrm{Sg}_{\mathrm{h}}
\end{aligned}
$$

Finally, the hourly and daily values for the ratio between the PAR and $S_{\mathrm{g}}$ extinction coefficients $\left(\beta_{\mathrm{h}}\right.$ and $\beta_{\mathrm{D}}$ respectively) were obtained as:

$$
\begin{aligned}
& \beta_{\mathrm{h}}=\mathrm{K}_{\mathrm{PAR}, \mathrm{h}} / \mathrm{K}_{\mathrm{Sg}, \mathrm{h}} \\
& \beta_{\mathrm{D}}=\mathrm{K}_{\mathrm{PAR}, \mathrm{D}} / \mathrm{K}_{\mathrm{Sg}, \mathrm{D}}
\end{aligned}
$$

\section{Corn crop}

The corn crop used in this study was grown near the cherry trees, with a planting distance of $0.10 \mathrm{~m}$ by 0.75 $\mathrm{m}$, within and between rows respectively, in near NorthSouth oriented rows. Measurements were made during early stages of development. The average leaf area per plant was estimated non-destructively several times during the experimental period using a laser area meter (CI-203 CID, Vancouver, Washington, USA), measuring all the leaves on 16 to 20 plants from the tip toward the base. The leaf area index was determined as well.

Measurements of simultaneous $\tau_{\mathrm{Sg}}$ and $\tau_{\mathrm{PAR}}$ were carried out on July 1 (DOY 183), July 7 (DOY 189), and July 16 (DOY 198) 2004, at two locations in the field. The first measurement set was obtained on a crop sowed on April 23, while the second and third set (July 7 and 16) corresponded to a second crop sowed on June 7. On those days, $\tau_{\text {PAR }}$ was determined hourly from 08:00 to 16:00 $\mathrm{h}$ (standard time), using the AccuPAR probe. At each hour, $\mathrm{PAR}_{\mathrm{h}}$ and $\mathrm{PAR}_{\mathrm{h} \downarrow}$ were determined as previously described for the cherry trees (now with a separation of $10.5 \mathrm{~cm}$ between positions). The same spacing applies for the solarimeter tubes used for $\tau_{\mathrm{Sg}}$ determinations. An additional solarimeter was placed above the canopies to register $\mathrm{Sg}_{\mathrm{h}}$. The solarimeters were connected to a datalogger, using a scan rate of $30 \mathrm{~s}$ averaged every 15 min. Only data for each hour, coincidental with PAR measurements, were used for analysis. Thus, $\tau_{\mathrm{PAR}, \mathrm{h}}$, $\tau_{\mathrm{PAR}, \mathrm{D}}, \mathrm{K}_{\mathrm{PAR}, \mathrm{h}}, \mathrm{K}_{\mathrm{PAR}, \mathrm{D}}, \tau_{\mathrm{Sg}, \mathrm{h}}, \tau_{\mathrm{Sg}, \mathrm{D}}, \mathrm{K}_{\mathrm{Sg}, \mathrm{h}}, \mathrm{K}_{\mathrm{Sg}, \mathrm{D}}, \beta_{\mathrm{h}}$, and $\beta_{\mathrm{D}}$ were computed as described earlier (Equations [3] to [12], only now the daily aggregation was obtained from $\mathrm{h}=1$ to 9 ).

The following methodologies apply for the conversion between $\tau_{\mathrm{PAR}}$ and $\tau_{\mathrm{Sg}}$. For the sake of space, mainly $\tau_{\mathrm{PAR}} \rightarrow \tau_{\mathrm{Sg}}$ is discussed, although the performance of the methods in each conversion was evaluated.
Calculation procedures for transmittance conversion: fixed-ratio of extinction coefficients

Campbell and Van Evert (1994) related values of fraction of interception (one minus transmission) of global solar radiation $\left(f_{\mathrm{Sg}}\right)$ to fraction of interception of PAR $\left(f_{\mathrm{PAR}}\right)$ for a plant canopy. In a follow-up analysis, and based on a Beer's law equation-type, Campbell (2004) proposed that the ratio $\tau_{\mathrm{Sg}} / \tau_{\mathrm{PAR}}$ can be obtained as:

$$
\tau_{\mathrm{Sg}} / \tau_{\mathrm{PAR}}=e^{-\left(\mathrm{k}_{\mathrm{gg}}-\mathrm{K}_{\mathrm{PAR}}\right) \mathrm{LAL}}
$$

Assuming a fixed ratio $(\beta) \mathrm{K}_{\mathrm{Sg}} / \mathrm{K}_{\mathrm{PAR}}=0.7$ (Campbell and Van Evert, 1994), Equation [13] can be rewritten as:

$$
\tau_{\mathrm{Sg}}=\tau_{\mathrm{PAR}} \mathrm{e}^{0.3 \mathrm{~K}_{\mathrm{PAR}} \mathrm{LAL}_{\mathrm{o}}}
$$

The use of Equation [14] requires knowing both $\mathrm{K}_{\mathrm{PAR}}$ and $\mathrm{LAI}_{0}$. However, from Equation [2]:

$$
\begin{gathered}
\mathrm{K}_{\mathrm{PAR}} \Omega=-\ln \left(\tau_{\mathrm{PAR}}\right) / \mathrm{LAI}_{\mathrm{o}} \\
\mathrm{K}_{\mathrm{Sg}} \Omega=-\ln \left(\tau_{\mathrm{Sg}}\right) / \mathrm{LAI}_{\mathrm{o}}
\end{gathered}
$$

and thus

$$
\mathrm{K}_{\mathrm{Sg}} / \mathrm{K}_{\mathrm{PAR}}=\ln \left(\tau_{\mathrm{Sg}}\right) / \ln \left(\tau_{\mathrm{PAR}}\right)
$$

Therefore, solving for $\tau_{\mathrm{sg}}$ and assuming that $\beta=0.7$, the expression becomes

$$
\tau_{\mathrm{Sg}}=e^{0.7 \ln \left(\tau_{\mathrm{PAR}}\right)}=\tau_{\mathrm{PAR}} 0,7
$$

Although Equation [18] is mathematically similar to Equation [14], it has the advantage of not requiring the knowledge of LAI. Thus, this method was selected and evaluated in this work, and is herein referred to as the "fixed-ratio" method.

\section{Calculation procedures for transmittances conversion: Kiniry's method}

Kiniry (1999) briefly discusses two methods to convert fraction of interception of $\mathrm{S}_{\mathrm{g}}\left(f_{\mathrm{Sg}}\right)$, "measured using a tube solarimeter", to fraction of interception of PAR $\left(f_{\mathrm{PAR}}\right)$, "measured using a PAR sensor", that produced nearly identical results. The first one was based on reported $\mathrm{K}$ values by Monteith and Unsworth (1990) for PAR and $\mathrm{S}_{\mathrm{g}}(-0.485$ and -0.65 respectively). He calculated, over a range of LAI from 0.1 to 3.0, a weighted mean value of 1.184 for the ratio $f_{\mathrm{PAR}} / f_{\mathrm{Sg}}$. The second method, based on Gates (1965) which relates radiation transmitted through a leaf as a function of wavelength, yields a value of 1.190 for the referred ratio. Thus, assuming an average value of 1.187, and given the fact that the interception 
fraction is the complement (to one) of the transmittance, we have:

$$
\tau_{\mathrm{Sg}}=0.842 \tau_{\mathrm{PAR}}+0.158
$$

This will be referred to as the "Kiniry's method", and as the fixed-ratio method, it does not require information of $\mathrm{LAI}_{0}$.

\section{Approaches performance}

The performance of the described methodologies was evaluated using graphical and statistical methods. The statistical indices (goodness of fit criteria) included the root mean square error (RMSE) and the relative RMSE or relative error (RE), the mean absolute error (MAE; Annandale et al., 2004); the Willmott index of agreement (D; Willmott, 1982); and the coefficient of residual mass (CRM; Loague and Green, 1991). These relationships have the following expressions:

$$
\begin{gathered}
\text { RMSE }=\sqrt{\left[\sum_{i=1}^{n}\left(\mathrm{P}_{i}-\mathrm{O}_{\mathrm{i}}\right)^{2}\right]} / \mathrm{n} \\
\mathrm{RE}(\%)=(100 \mathrm{RMSE}) / \mathrm{Oavg} \\
\mathrm{MAE}=\frac{\frac{1}{\mathrm{n}} \sum_{\mathrm{i}=1}^{\mathrm{n}} \mathrm{Abs}(\mathrm{Pi}-\mathrm{Oi})}{\mathrm{O}} 100 \\
\mathrm{D}=1-\frac{\sum_{\mathrm{i}=1}^{\mathrm{n}}(\mathrm{Pi}-\mathrm{Oi})^{2}}{\sum_{\mathrm{i}=1}^{\mathrm{n}}\left(|\mathrm{Pi}-\mathrm{O}|+\left|\mathrm{O}_{\mathrm{i}}-\mathrm{O}\right|\right)^{2}} \\
\mathrm{CMR}=\left(\sum_{\mathrm{i}=1}^{\mathrm{n}} \mathrm{Oi}-\sum_{\mathrm{i}=1}^{\mathrm{n}} \mathrm{Pi}\right) / \sum_{\mathrm{i}=1}^{\mathrm{n}} \mathrm{Oi}
\end{gathered}
$$

where $\mathrm{Pi}$ and $\mathrm{Oi}$ are the simulated and measured transmittances; $\mathrm{n}$ is the number of pairs of data (both observed and predicted values), and $\mathrm{O}$ is the mean of the measured values. The optimal values of RMSE, RE, MAE and CRM criteria are zero. For D, a value of one expresses perfect agreement between $\mathrm{Oi}$ and $\mathrm{Pi}$ whereas zero describes complete disagreement. The RMSE is dimensionless, and RE and MAE are in percentage. Positive values of CRM indicate that the model underestimates the measurements, whereas negative values indicate overestimates. All the analyses were made in Excel (Microsoft Inc.).

\section{RESULTS AND DISCUSSION}

\section{Radiation transmittance relations}

Hourly transmittance values were at their maximum around noon, when a relative higher proportion of the incoming radiation passes unobstructed through inter- canopy gaps, and at their minimum in early morning and late afternoon (Figure 2). Thus, when comparing the daily average of transmittance, either PAR or $S_{g}$, with hourly-instantaneous measurements, differences are found. Therefore, it is possible to argue that instantaneous, around-noon measurements of radiation transmittance, as is rather commonly reported in crop light capture- or RUE-related studies (e.g. Gallo et al., 1993; Yunusa et al., 1993; Lizaso et al., 2003) may not be a good practice when these studies are done on discontinuous canopies such as fruit trees or horticultural crops in their early stages of development, confirming the theoretical results of Sinclair (2006). In fact, $\tau_{\mathrm{PAR}}$ and $\tau_{\mathrm{Sg}}$ measurements performed around noon tended to be higher than the daily weighted average, potentially introducing errors if the former are taken as representative of the overall daily situation. This is especially true for clear days with a high beam fraction in the incoming radiation that is able to penetrate through canopy (or inter-rows) gaps and reach the orchard floor during the central hours of the day. These ideas had been suggested before (Flenet et al., 1996; Sinclair and Muchow, 1999), but they tend to be, in general, overlooked (Yunusa et al., 1997; Kiniry et al., 1998; Kiniry, 1999).

The general pattern was similar for all the measurement dates, with minor differences being detected for two situations: cherries on June 1 and corn on July 7. The former (Figure 2B) is a consequence of the particular cloudiness dynamic of that day. Although all measurement days can be classified as clear sky based on the daily total amount of incoming radiation (Table 1), June 1 presented intermittent episodes of clouds passing through the day. The presence of clouds enhances solar radiation scattering and reduces the relative importance of the beam fraction of the incoming radiation. Under such conditions, radiation comes from several directions from the sky and not a single source, as is the case under clear-sky conditions. Thus, the presence of gaps has a lesser effect on the transmittance of radiation reaching the orchard floor. In the case of corn on July 7 (Figure 2E), the high transmittance values obtained were likely a consequence of early stage of the crop development with low leaf area index (LAI), allowing a large amount of incoming radiation to penetrate and reach the soil surface, not only at solar noon but for an extended period through the day.

Transmittance was higher for global radiation than for PAR, a natural consequence of the different optical properties of leaves for PAR and $\mathrm{S}_{\mathrm{g}}$ (Szeicz, 1974; Yunusa et al., 1993). Thus, the ratio $\tau_{\mathrm{Sg}} / \tau_{\mathrm{PAR}}$ was always higher than one. Moreover, this ratio is not constant, being generally higher early and late on the day and lower around noon. The differences in transmittance are highly 


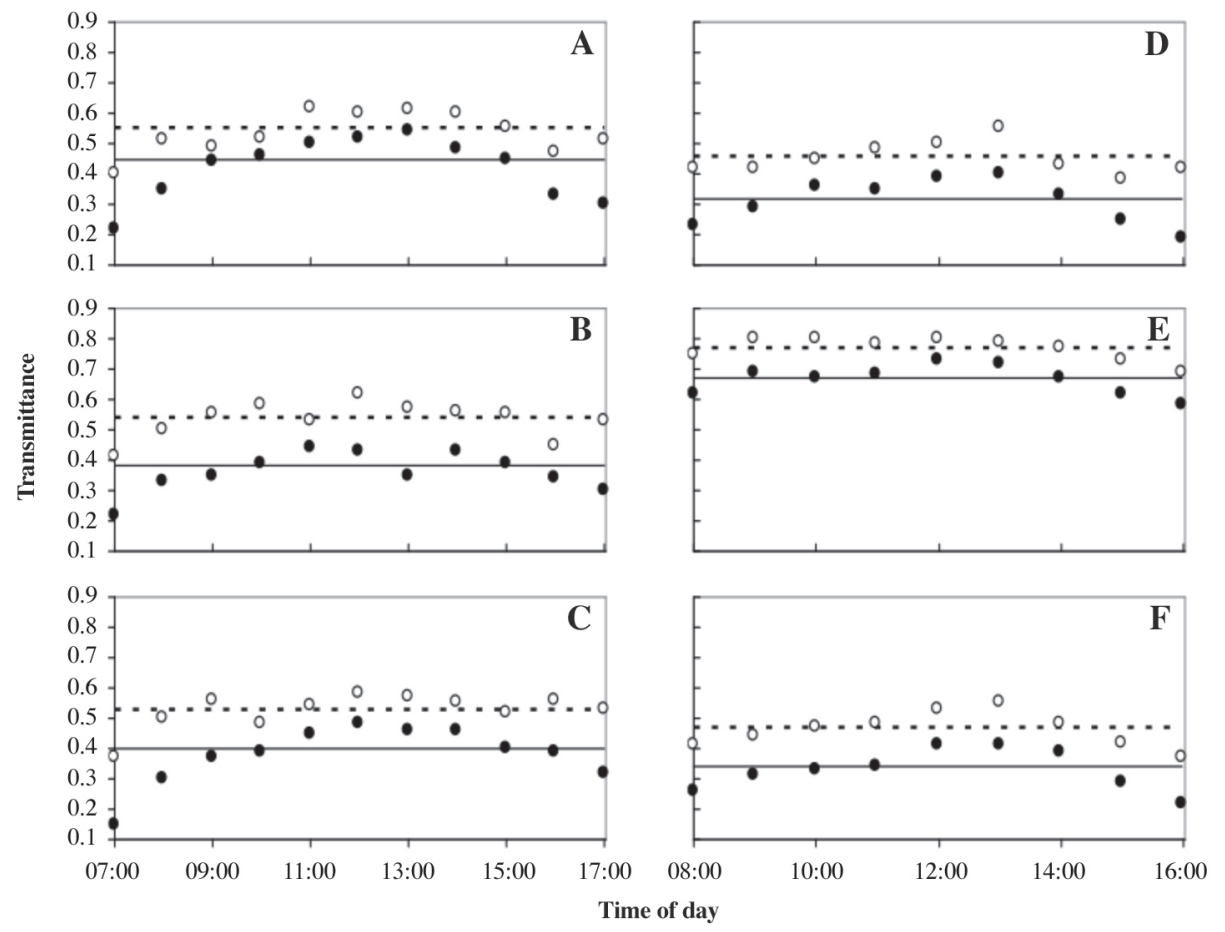

Figure 2. Hourly global solar radiation transmittance $\left(\tau_{\mathrm{Sg}}\right)$ (open circles) and photosynthetically active radiation (PAR) transmittance $\left(\tau_{\mathrm{PAR}}\right)$ (filled circles) and daily averaged $\tau_{\mathrm{Sg}}$ (segmented line) and $\tau_{\mathrm{PAR}}$ (solid line) as determined from field measurements on the cherry orchard (panels A, B, and C) and corn (panels D, E, and F).

dependant on the differential leaf optical properties, especially early or late in a day, since beam radiation is "forced" to pass through the canopies given the large zenith angle. Around noon, the proportion of incoming radiation (either $\mathrm{Sg}$ or PAR) that passes unobstructed through canopy gaps (either within or inter rows) is higher, reducing the effect of different optical properties of leaves for the different wavelengths and tending to make $\tau_{\mathrm{sg}}$ and $\tau_{\text {PAR }}$ more similar.

\section{Performance of transmittance conversion methods}

The first step was to verify the validity of the 0.7 value for $\beta$, the ratio of extinction coefficients for $S_{g}$ and PAR, as an expression of the effect of leaves optical properties. Thus, $\beta$ was initially calculated considering for each hour only the below-canopy measurements positions, both for $\mathrm{S}_{\mathrm{g}}$ and PAR that were completely shaded by the plants. Since on July 7 (DOY 189) the corn foliage coverage was extremely low, this day was initially excluded from this analysis as it was impossible to characterize any measurement position as completely shaded at any time of the day. Despite some variability at certain hours, the general trend of the hourly values was normally around 0.55-0.75 (Figure 3). Daily averages were around 0.65 (Table 2). It should be noted that all these values include, to some extent, the effect of plant parts other than leaves such as branches, fruit (for cherry trees) and dead leaves, all of them affecting radiation transmittance conditions.

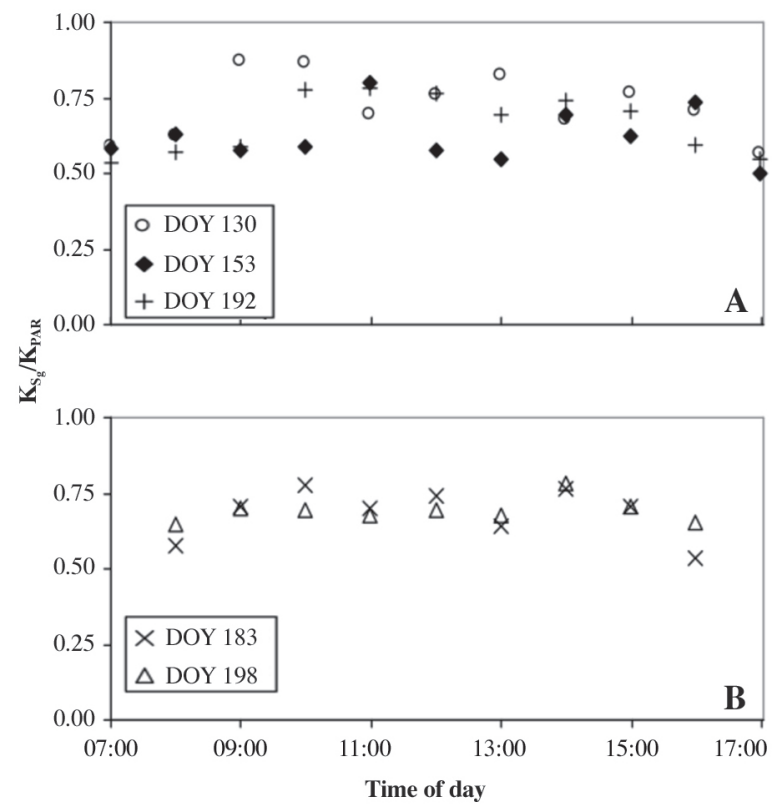

Figure 3. Hourly variation in the ratio of extinction coefficients for global solar radiation $\left(S_{g}\right)$ and photosynthetically active radiation $(\mathbf{P A R}) \mathrm{K}_{\mathrm{Sg}} / \mathrm{K}_{\mathrm{PAR}}$ for cherry trees (panel A) and corn (panel B) for the different days of measurements, considering only shadowed below-canopy positions. 
Table 2. Average daily values of $K_{\mathrm{Sg}} / \mathrm{K}_{\mathrm{PAR}}$ and standard deviation (SD) determined only at the shadowed positions.

\begin{tabular}{llcl}
\hline Crop & Date & Average & SD \\
\hline Cherry & May 9 & 0.66 & 0.10 \\
& June 1 & 0.63 & 0.09 \\
& July 10 & 0.64 & 0.06 \\
Corn & July 1 & 0.66 & 0.09 \\
& July 21 & 0.65 & 0.06 \\
\hline
\end{tabular}

However, these particular effects are highly difficult to separate and quantify in actual field situations. Therefore, although we included different canopies such as cherry and corn, a value around 0.65 for $\beta$, such as the 0.7 figure proposed by Campbell and Van Evert (1994) seems to be accurate enough for its use in general applications and on a daily basis. Moreover, when considered all the below-canopy positions in the calculations (i.e. not only the shaded ones), there were no major differences in the extinction coefficients ratio despite of the variable relative importance of gaps between canopies at different times, even when there were differences in transmittance throughout the days (data not shown). Indeed, the variability in radiation transmittance for PAR and $\mathrm{S}_{\mathrm{g}}$ through the day (Figure 2 ) does not extend in the same magnitude to the ratio of their extinction coefficients. Thus, the value of 0.70 for $\mathrm{K}_{\mathrm{Sg}} / \mathrm{K}_{\mathrm{PAR}}$ may be extended to general situations, including discontinuous canopies.

Finally, Table 3 presents the results obtained when using the two reported methods for the conversion of transmittances. In general, the methods behave similarly when used for either $\tau_{\mathrm{PAR}} \rightarrow \tau_{\mathrm{Sg}}$ or $\tau_{\mathrm{Sg}} \rightarrow \tau_{\mathrm{PAR}}$. Also, for low values of transmittance, e.g., less than 0.45 , both methods tend to perform rather similarly (Figure 4A). However, differences were evident for transmittance values higher than 0.45 . This is likely to be due to the fact that the Kiniry's method is not flexible, in terms of the relation between $\tau_{\mathrm{PAR}}$ and $\tau_{\mathrm{Sg}}$. While the coefficients used in Kiniry's linear relationship may be good enough for low values of $\tau_{\mathrm{PAR}}$, as the transmittance gets higher, $\tau_{\mathrm{Sg}}$ should be more similar to $\tau_{\mathrm{PAR}}$, where the extreme case is when all radiation is transmitted, and therefore, $\tau_{\mathrm{Sg}}$ approaches $\tau_{\mathrm{PAR}}$. This situation is not accounted for in the approach derived from Kiniry's analysis. The fixed-ratio method therefore outperformed Kiniry's method. The same behavior was observed on a daily time scale (Figure 4B). We found that it does not make an important difference to use 0.65 or 0.7 for $\beta$ when using the fixed-ratio method (result not shown). Thus, unless there are field determinations of leaf optical properties for a given crop, the general use of 0.7 and the fixed ratio approach are adequate.
Table 3. Comparison of performance of the two methods used for transmittance conversion (average CRM, both hourly and daily, correspond to absolute values).

\begin{tabular}{|c|c|c|c|}
\hline & \multirow{2}{*}{$\begin{array}{l}\text { Performance } \\
\text { index }\end{array}$} & \multicolumn{2}{|c|}{ Method } \\
\hline & & Fixed-ratio & Kiniry \\
\hline \multicolumn{4}{|l|}{$\tau_{\mathrm{PAR}} \rightarrow \tau_{\mathrm{Sg}}$} \\
\hline \multirow[t]{5}{*}{ Hourly $(n=60)$} & RMSE & 0.04 & 0.06 \\
\hline & $\operatorname{RE}(\%)$ & 8.19 & 10.29 \\
\hline & $\operatorname{MAE}(\%)$ & 6.32 & 8.33 \\
\hline & D & 0.96 & 0.94 \\
\hline & CRM & 0.03 & 0.08 \\
\hline \multirow[t]{5}{*}{ Daily $(n=6)$} & RMSE & 0.02 & 0.04 \\
\hline & $\operatorname{RE}(\%)$ & 3.20 & 7.10 \\
\hline & $\operatorname{MAE}(\%)$ & 2.55 & 6.52 \\
\hline & D & 0.99 & 0.96 \\
\hline & CRM & 0.01 & 0.07 \\
\hline \multicolumn{4}{|l|}{$\tau_{\mathrm{Sg}} \rightarrow \tau_{\mathrm{PAR}}$} \\
\hline \multirow[t]{5}{*}{ Hourly $(n=60)$} & RMSE & 0.05 & 0.07 \\
\hline & $\mathrm{RE}(\%)$ & 11.44 & 16.28 \\
\hline & MAE $(\%)$ & 8.98 & 13.19 \\
\hline & $\mathrm{D}$ & 0.98 & 0.95 \\
\hline & CRM & -0.04 & -0.012 \\
\hline \multirow[t]{5}{*}{ Daily $(n=6)$} & RMSE & 0.02 & 0.05 \\
\hline & $\operatorname{RE}(\%)$ & 3.50 & 8.44 \\
\hline & MAE $(\%)$ & 3.57 & 10.04 \\
\hline & $\mathrm{D}$ & 0.99 & 0.97 \\
\hline & CRM & -0.02 & -0.10 \\
\hline
\end{tabular}

Average

Hourly

$\begin{array}{ccc}\text { RMSE } & 0.05 & 0.06 \\ \text { RE (\%) } & 9.85 & 13.29 \\ \text { MAE (\%) } & 7.65 & 10.76 \\ \text { D } & 0.97 & 0.95 \\ \text { CRM } & |0.03| & |0.10| \\ \text { RMSE } & 0.02 & 0.04 \\ \text { RE (\%) } & 3.35 & 7.77 \\ \text { MAE (\%) } & 3.06 & 8.28 \\ \text { D } & 0.99 & 0.97 \\ \text { CRM } & |0.05| & |0.09|\end{array}$

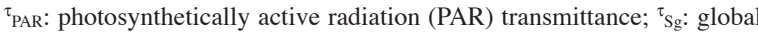
solar radiation $\left(\mathrm{S}_{\mathrm{g}}\right)$ transmittance; RMSE: root mean square error; RE: relative error; MAE: mean absolute error; D: Willmott index of agreement; CRM: coefficient of residual mass. 

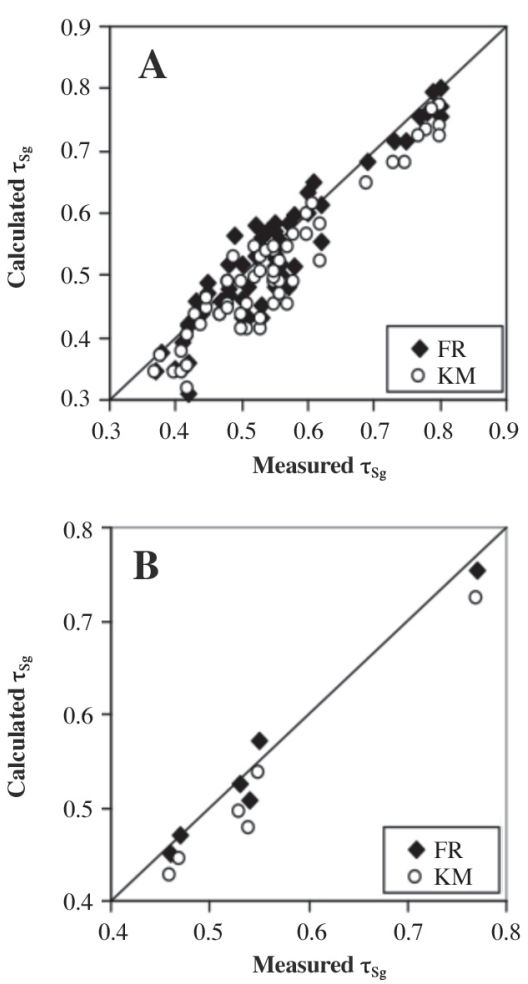

Figure 4. Comparison of global solar radiation transmittance $\left(\tau_{S g}\right)$ measured and simulated using the fixed-ratio method (FR) and Kiniry's method (KM) for hourly (panel A) and daily (panel B) time scale.

\section{CONCLUSIONS}

Transmittance of both global solar radiation and PAR through discontinuous canopies proved to be affected by the optical properties of the leaves of the crop (cherry trees, corn) to the corresponding wavelength, by the existence of gaps between canopies, and the relative importance of the beam fraction of the incoming radiation. Nonetheless, the use of a value of 0.7 for the ratio of extinction coefficients appeared valid for both shadowed situations and noncomplete covering canopies.

Regarding the conversion of transmittances for different wavelengths, the methods proposed generally performed properly for the different experimental conditions considered. The method based on a fixed value for the ratio of extinction coefficients outperformed Kiniry's method both hourly (average RE $=7.97 \%$ and $13.29 \%$ respectively) and daily (average $\mathrm{RE}=2.84 \%$ and $7.77 \%$ respectively). The former is a simple and suitable method to convert transmittance values of PAR and $\mathrm{Sg}$ at different time-scales and canopy-coverage conditions.

\section{ACKNOWLEDGEMENTS}

This research was partially funded through the project FONDEF D021-1146. The technical assistance of A. Milla in the field data acquisition is greatly appreciated as well as special collaboration given by E. Quiroz, C. Kremer and A. Kemanian during the installation and setup process of the solarimeters. The paper benefited from the comments of anonymous reviewers and the editor.

\section{RESUMEN}

Determinación en terreno de la relación entre la transmitancia de radiación solar global y radiación fotosintéticamente activa (PAR) a través de coberturas vegetales discontinuas. En muchos modelos, la transmisión de radiación a través de la canopia es descrita como un proceso de atenuación exponencial (Ley de Beer), la cual se asume válida para coberturas vegetales completas y con una distribución aleatoria de hojas. Sin embargo, para canopias discontinuas ocurre una situación más compleja debido a la presencia de espacios entre las plantas. Esto debe ser considerado cuando se caracterizan aspectos de radiación en este tipo de sistemas, especialmente cuando es de interés a una escala de tiempo pequeña. La transmisión de radiación fotosintéticamente activa PAR ( $\tau_{\mathrm{PAR}}$ ) es más típicamente estudiada y mencionada que la transmisión de radiación solar $S_{\mathrm{g}}\left(\tau_{\mathrm{Sg}}\right)$. Sin embargo, tanto PAR como $\mathrm{S}_{\mathrm{g}}$ son importantes en los sub-modelos de radiación que suelen formar parte de los programas usados para simular el crecimiento de cultivos. En este trabajo se realizaron mediciones simultáneas de $\tau_{\mathrm{Sg}}$ y $\tau_{\mathrm{PAR}}$, y se caracterizó la variación horaria en la transmitancia de PAR y $\mathrm{S}_{\mathrm{g}}$. Dos métodos fueron evaluados para realizar la transformación entre $\tau_{\mathrm{Sg}}$ y $\tau_{\mathrm{PAR}}$. Ambos enfoques dieron resultados similares para condiciones de baja transmitancia, pero difieren para valores elevados de ésta. El metodo basado en una razón fija de los coeficientes de extinctión de PAR y $S_{\mathrm{g}}$ se desempeñó mejor que aquel basado en una relación lineal entre $\tau_{\mathrm{PAR}}$ y $\tau_{\mathrm{Sg}}$, con un error relativo promedio de $7.97 \%$ vs. $13.29 \%$ y $2.84 \%$ vs. $7.77 \%$, respectivamente, para escalas de tiempo horarias y diarias.

Palabras clave: interceptación de radiación, coeficiente de extinción, modelo de simulación de cultivos.

\section{LITERATURE CITED}

Annandale, J.G., N.Z. Jovanovic, G.S. Campbell, N. Du Santoy, and P. Lobit. 2004. Two-dimensional solar radiation interception model for hedgerow fruit trees. Agricultural and Forest Meteorology 121:207-225. 
Bonhomme, R. 2000. Beware of comparing RUE values calculated from PAR vs. solar radiation or absorbed vs. intercepted radiation. Field Crops Research 68:247-252.

Campbell, G.S. 2004. Use of the AccuPAR ceptometer to quantify effects of riparian vegetation removal on stream energy balance. Available at http://www. decagon.com/assets/Uploads/Use-of-the-AccuPARCeptometer-to-Quantify-Effects-of-RiparianVegetation-Removal-on-Stream-Energy-Balance.pdf (accessed 27 July 2010).

Campbell, G.S., and J.M. Norman. 1998. An introduction to environmental biophysics. 286 p. Springer-Verlag, New York, USA.

Campbell, G.S., and F.K. Van Evert. 1994. Light interception by plant canopies: Efficiency and architecture. p. 35-52. In Monteith, J.L., R.K. Scott, and M.H. Unsworth (eds.) Resource capture by crops. Nottingham University Press, Nottingham, UK.

Castellan-Estrada, M. 2001. Repartition de la biomasse chez Vitis vinifera L.; rendement de conversión du rayonnement solaire global et couts energetiques. Ph.D. Thesis. Institut National Agronomique, ParisGrignon, France.

Cohen, S., R.S. Rao, and Y. Cohen. 1997. Canopy transmittance inversion using a line quantum probe for a row crop. Agricultural and Forest Meteorology 86:225-234.

Flenet, F., J.R. Kiniry, J.E. Board, M.E. Westgate, and D.C. Reicosky. 1996. Row spacing effects on light extinction coefficients of corn, sorghum, soybean, and sunflower. Agronomy Journal 88:185-190.

Gallo, K.P., C.S.T. Daughtry, and C.L. Wiegand. 1993. Errors in measuring absorbed radiation and computing crop radiation use efficiency. Agronomy Journal 85:1222-1228.

Gates, D.M. 1965. Radiant energy, its receipt and disposal. In Waggoner, P.E. (ed.) Agricultural meteorology. Chapter 1 (Meteorological Monographs 6:1-26). American Meteorological Society, Boston, Massachusetts, USA.

Jovanovic, N.Z., and J.G. Annandale. 2000. Crop growth model parameters of 19 summer vegetables cultivars for use in mechanistic irrigation scheduling models. Water SA 26:67-76.

Jovanovic, N.Z., J.G. Annandale, and N.C. Mhlauli. 1999. Field water balance and SWB parameter determination of six winter vegetable species. Water SA 25:191-196.

Kiniry, J.R. 1999. Response to questions raised by Sinclair and Muchow. Field Crops Research 62:245-247.
Kiniry, J.R., J.A. Landivar, M. Witt, T.J. Gerik, J. Cavero, and L.J. Wade. 1998. Radiation-use efficiency response to vapor pressure deficit for maize and sorghum. Field Crops Research 56:265-270.

Landsberg, J.J., and F.J. Hingston. 1996. Evaluating a simple radiation/dry matter conversion model using data from Eucalyptus globulus plantations in Western Australia. Tree Physiology 16:801-808.

Lizaso, J.I., W.D. Batchelor, M.E. Westgate, and L. Echarte. 2003. Enhancing the ability of CERESMaize to compute light capture. Agricultural Systems 76:293-311.

Loague, K., and R.E. Green. 1991. Statistical and graphical methods for evaluating solute transport models: Overview and application. Journal of Contaminant Hydrology 7:51-73.

Marcos, J. 2000. Simulation-based assessment of alternative crops in the dryland Pacific Northwest. Ph.D. Dissertation. Washington State University, Pullman, Washington, USA.

Mariscal, M.J., F. Orgaz, and F.J. Villalobos. 2000. Radiation-use efficiency and dry matter partitioning of a young olive (Olea europaea) orchard. Tree Physiology 20:65-72.

Monteith, J.L. 1994. Validity of the correlation between intercepted radiation and biomass. Agricultural and Forest Meteorology 68:213-220.

Monteith, J.L., and M.H. Unsworth. 1990. Principles of environmental physics. 440 p. Edward Arnold, London, UK.

Sattin, M., R. Milne, J.D. Deans, and P.G. Jarvis. 1997. Radiation interception measurement in poplar: sample size and comparison between tube solarimeters and quantum sensors. Agricultural and Forest Meteorology 85:209-216.

Sinclair, T.R. 2006. A reminder of the limitations in using Beer's law to estimate daily radiation interception by vegetation. Crop Science 46:2343-2347.

Sinclair, T.R., and R.C. Muchow. 1999. Occam's razor, radiation-use efficiency, and vapor pressure deficit. Field Crops Research 62:239-243.

Stöckle, C.O., and J. Jara. 1998. Modeling transpiration and soil water content from a corn (Zea maize L.) field: 20 min vs. daytime integration step. Agricultural and Forest Meteorology 92:119-130.

Szeicz, G. 1974. Solar radiation in crop canopies. Journal of Applied Ecolology 11:617-636.

Thornley, J.H.M., and J.R. Johnson. 1990. Plant and crop modeling. A mathematical approach to plant and crop physiology. 669 p. Oxford University Press, Oxford, UK. 
Weiss, A., and J.M. Norman. 1985. Partitioning solar radiation into direct and diffuse, visible and near infrared components. Agricultural and Forest Meteorology 34:205-213.

Whiting, M.D. 2001. Whole canopy source-sink relations and fruit quality in 'Bing' sweet cherry trees on a dwarfing, precocious rootstock. Ph.D. Dissertation. Washington State University, Pullman, Washington, USA.

Willmott, C.J. 1982. Some comments on the evaluation of model performance. Bulletin of the American Meteorological Society 63:1309-1313.
Yunusa, I.A.M., K.H.M. Siddique, R.K. Belford, and M.M. Karimi. 1993. Effects of canopy structure on efficiency of radiation interception and use in spring wheat cultivars during the pre-anthesis period in a mediterranean-type environment. Field Crops Research 35:113-122.

Yunusa, I.A.M., R.R. Wlaker, and D.H. Blackmore. 1997. Characterization of water use by Sultana grapevines (Vitis vinifera L.) on their own roots or on Ramsey rootstock drip-irrigated with water of different salinities. Irrigation Science 17:77-80. 